\title{
Monitoring vegetation drought using MODIS remote sensing indices for natural forest and plantation areas
}

\begin{abstract}
Natural forest, oil palm and rubber plantations are economically and environmentally important for Peninsular Malaysia. The present study analysed four years of moderateresolution imaging spectroradiometer (MODIS) surface reflectance data to develop spectral indices of vegetation, water availability and moisture stress for the study area. The indices $\ddot{i}$ the Normalised Difference Vegetation Index, the Normalised Difference Water Index and the Moisture Stress Index $\ddot{i}$ were applied to the three different habitats to monitor drought and develop a Malaysia Southwest Monsoon (M-SWM) classification. By integrating indicators of the Southwest Monsoon, the Standard Precipitation Index, mean precipitation and temperature and spectral indices correlation analysis, M-SWM classification showed greater sensitivity to drought conditions than any of the individual indicators alone. The results also found that July is the driest month; it was the only period classified as óVery Dryôbased on the M-SWM.
\end{abstract}

Keyword: Drought indices; MODIS; Southeast Asia 